natural selection in preserving nations. Our gaze is too intently fixed on the individual struggle, and we are more ready to revert to old abstract notions of inner springs and guides, set for some noble and unknowable purpose, than to develop the one fruitful idea of progress by the natural and predictable interaction of parts. ARTHUR EBBELS. February 16.

\section{THE ORGANISATION OF FISHERY RESEARCH. ${ }^{1}$}

I N August, Igor, a committee, since known as the Committee on Ichthyological Research, was appointed by the Board of Trade in order " to inquire and report as to the best means by which the State or local authorities can assist scientific research as applied to problems affecting the fisheries of Great Britain and Ireland, and in particular whether the object in view would best be attained by the creation of one central body or department acting for England, Scotland, and Ireland, or by means of separate departments or agencies in each of the three countries." The report of this committee, together with the minutes of evidence laid before it, has now been published.

The appointment of a committee of inquiry by Government is, I am afraid, generally regarded as having the effect of postponing, or even avoiding, any effective action on their part. In the present case, however, we have the somewhat exceptional situation of real action being taken whilst the inquiry was still in progress, and that action in a direction which is, to some extent, at variance with the course eventually recommended by the committee. For whilst the Ichthyological Committee were still engaged in hearing the evidence of experts of various degrees of authority, and by all the subtleties of cross-examination causing them to commit themselves-as is plainly indicated in the evidence of most of the witnesses-to statements which, after a little reflection and in more collected and rational moments they would rather have expressed differently, the Government decided to take part in the scheme of international investigations which was receiving somewhat rough treatment at the hands of the committee, and persuaded Parliament to vote considerable sums of money for that purpose. The Government are to be congratulated upon having taken definite practical action, even though a minor result of that action has been to cause the report of their Ichthyological Committee to be brought, as it were, with but enfeebled vitality into the world.

The question referred to the committee was, nevertheless, one of considerable importance, and their answer to it-if not of immediate moment-will probably be not without influence in the future. In a general way, the question how the State or local authorities can best assist scientific research as applied to fisheries is quite simply answered by saying that they can do so by supplying the most capable and trust. worthy scientific men whose services they can obtain with the necessary funds to carry out such research. The only real difficulty is to find some scheme of organisation which will ensure that the men employed are both naturally and by experience and training the best fitted for the work, that thorough, accurate and really scientific workers are distinguished from such as are ostentatious and superficial, and that those failing to maintain their efficiency, or to carry out the work assigned to them, are speedily eliminated.

Two other matters of importance are, however, involved in the terms of reference of the committee. In the first place, what should be the exact relations

1 Report of the Committee on Ichthyological Research. (London: Eyre

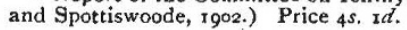

No. I 740 , vOL. 67$]$ existing between the men charged with carrying out scientific research and those whose duties are connected with fishery administration; and, in the second place, to what extent is it advantageous that the researches carried on in different parts of the United Kingdom should be placed under one central control.

On the subject of the relations of the administrative and scientific departments, the committee express a quite clear and definite view. They are of opinion that the responsibility for and the control of the scientific investigations should be in the hands of the central administrative authority, and that the most important of the researches should be directly carried out by this authority. In suggesting a new arrangement for England, they, however, propose the establishment of a central council, composed, ir approximately equal numbers, of administrative and scientific men, whose duty it should be to advise the administrative authority (Board of Trade) on all matters concerning scientific research. No provision is suggested by means of which this council could enforce its decisions.

In my opinion, it is open to the gravest doubt whether such a direct control of scientific work by an administrative body is likely to lead to satisfactory results. The trustworthy in'ormation and assistance required by the administrative body are, 1 feel sure, much more likely to be obtained from a more independent scientific authority acting as advisers to the administrators, an authority the preponderating influence of which is in the hands of recognised men of science. Such an arrangement will render the selection of capable naturalists far more probable, and will ensure the naturalists being in a position to give that complete concentration of their whole energies upon the problem in hand which is so absolutely essential to successful scientific work. The claims of administration are immediate and pressing, and when they are combined with the claims of scientific research, experience has repeatedly shown that the latter are bound, sooner or later, to take a secondary place. Huxley's experiences as an inspector of fisheries are a sufficient illustration of this point.

The objection urged by the opponents of the view here advocated is that the method is less likely to lead to immediate practical results. Unfortunately, there is no short and easy road to results which are sound and scientific, and the adage "More hurry, less speed" is, I fear, more than usually applicable to work of this kind.

On the second question-a question to which the attention of the committee was particularly directednamely, to what extent there should be central control of the investigations throughout the United Kingdom, the committee also make a definite recommendation. Recognising the fact that separate administrative authorities are already established in England, Scotland, and Ireland, and in view of their opinion that the scientific investigations should be controlled by the administrative authority, the committee consider that the researches in the three portions of the kingdom are best kept separate. In order, however, to secure some measure of uniformity of action amongst the three bodies, they propose the establishment of a quarterly conference of experts representing the English, Scottish, and Irish departments. But there seems little likglifhood that such a conference, which, as in the case of the English council; it is not proposed to endow either with authority to enforce its decisions or with any power of action of its own, would be an instrument of much effective value. The scheme is in part the result of a desire, with which I entirely sympathise, to ensure to the workers the maximum of freedom and individual initiative, combined with such centralisation as shall prevent undue or unnecessary waste of energy. But would not these objects be attained more effectually 
and simply by the appointment of a single individual, in whom responsibility could be fixed, and under whose general direction the heads of the scientific departments in the three portions of the United Kingdom would act, a considerable measure of individual authority and initiative being at the same time accorded to each?

Whatever scheme may be adopted, it seems to me to be the duty of all naturalists to insist that the preponderating control of the investigations, as I have already urged, shall be in the hands of recognised men of science, for unless this is so there can be no guarantee that they will be carried out by scientific methods and with that accuracy and thoroughness without which no results of any permanent value can ever be obtained.

E. J. Allen.

\section{MAGNETIC WORK IN NEW ZEALAND}

$T \mathrm{HE}$ "Report of the Department of Lands and Survey, New Zealand," for I9OI-2 contains an account of the new magnetic observatory erected in Christchurch,

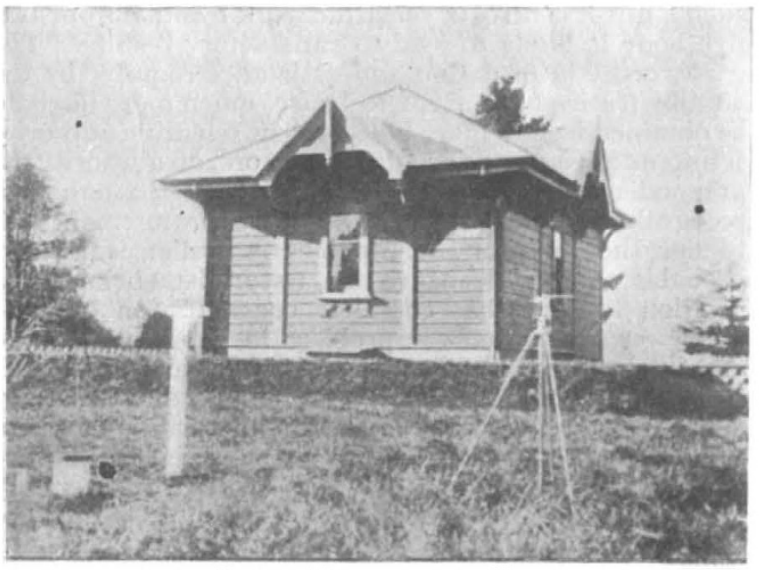

FIG. 1.-Magnetograph House.

New Zealand, and of the magnetic work to be carried on there under the direction of Dr. Coleridge Farr. The site of the observatory buildings in Hagley Park appears, from the illustrations in the Survey "Report," to be one of considerable natural beauty. It would also seem to be very suitable from a magnetic standpoint, if we may judge from the preliminary survey carried out by Dr. Farr in the neighbourhood of Dunedin, In. vercargill, Nelson and Christchurch. Of all the districts examined, he found the vicinity of Christchurch the most free from local disturbances.

The observatory consists of three separate buildings, externally of the Swiss chalet type. Photographs of two of these are here reproduced from the Survey "Report." Fig. I shows the magnetograph house, or, to be strictly accurate, the superstructure above the underground cellar in which the magnetographs are lodged. Fig. 2 shows the office buildings, which also serve to accommodate a seismograph. The third building, not shown here, serves for the taking of the absolute magnetic observations.

The magnetic equipment of the observatory consists of a self-recording magnetograph by Adie and a unifilar magnetometer and dip circle by Dover, all of the ordinary NO. 1740 , vOL. 67$]$
Kew pattern, and examined, prior to their dispatch to New Zealand, at the National Physical Laboratory (Kew Observatory). In addition, Dr. Farr has temporarily the loan of a second unifilar and dip circle belonging to the Royal Society, intended primarily for survey work. Be. sides the magnetic instruments, the observatory possesses a Milne seismograph, a Kelvin water-dropper and two portable electrometers, for determinations of atmospheric electric potential, and a "dissipation apparatus" of the type invented by Elster and Geitel for determining the rate of loss of electric charges from an insulated body.

After the arrival of the magnetograph in New Zealand, Dr. Farr had the clock modified so as to allow of rapid as well as slow rotation of the drum carrying the photo. graphic paper. This slight modification - which has been made independently by the directors of the Melbourne and Mauritius Observatories-admits of open time-scale traces being obtained as satisfactorily with the ordinary Kew pattern magnetograph as with the newer types by Eschenhagen and others. This modification has allowed 1)r. Farr to participate fully in the international scheme of magnetic observations agreed on in connection with the present German and British Antarctic expeditions. In fact, during the call of the British vessel, the Discovery, at New Zealand, he arranged with Commander Scott an extension of the scheme of rapid registration, which it is hoped may increase its usefulness. The modification of the clock presented Dr. Farr with an opportunity of an unexpected character, of which full use was made. Zealously aided by his assistant, Mr. Skey-at what must have been considerable personal inconvenience-he succeeded in getting a practically continuous quick-run record for eighty hours during the occurrence of a succession of earthquake shocks. Part of one of the magnetic curves is reproduced in the "Report," showing a curious sinuous trace, and a complete comparison of the corresponding records from the magnetograph and seismograph may be expected to elicit valuable information as to the nature and cause of the movement of magnets at times of earthquake. The frequent repetition of such an opportunity is, perhaps, hardly to be desired, but there can be no doubt that in New Zealand, at least, the com. bination of magnetic and seismological investigations is a happy one.

Previous to the existence of the new institution, there was in the whole of Australasia only one magnetic

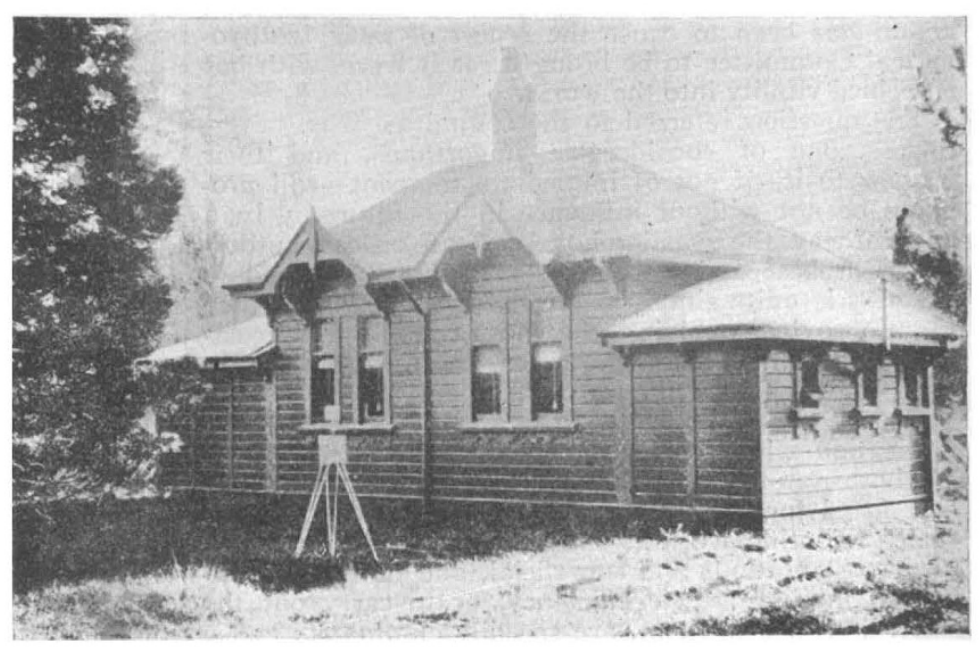

Fig. 2. - Office and Seismograph Room.

observatory, that at Melbourne. This fact and the general scarcity of such observatories in the southern hemisphere make the observatory at Christchurch of 